4 Kato TA, Shinfuku N, Sartorius N, Kanba S. Are Japan's hikikomori and depression in young people spreading abroad? Lancet. 2011; 378:1070.

5 Kato TA, Tateno M, Shinfuku N, Fujisawa D, Teo AR, Sartorius N, et al. Does the 'hikikomori' syndrome of social withdrawal exist outside Japan? A preliminary international investigation. Soc Psychiatry Psychiatr Epidemiol. 2012;47:1061-75.

6 Kato TA, Kanba S, Teo AR. Hikikomori: experience in Japan and international relevance. World Psychiatry. 2018;17:105-6.

7 Gondim FA, Aragão AP, Holanda Filha JG, Messias EL. Hikikomori in Brazil: 29 years of voluntary social withdrawal. Asian J Psychiatr. 2017;30:163-4.

8 Prioste CD, de Siqueira RC. Fetichismo virtual na vida de um Hikikomori brasileiro: um estudo de caso. Rev Bras Psicol Educ. 2019; 21:4-16.

9 Kato TA, Kanba S, Teo AR. Defining pathological social withdrawal: proposed diagnostic criteria for hikikomori. World Psychiatry. 2020; 19:116-7.

10 Nagata T, Yamada H, Teo AR, Yoshimura C, Nakajima T, van Vliet I. Comorbid social withdrawal (hikikomori) in outpatients with social anxiety disorder: clinical characteristics and treatment response in a case series. Int J Soc Psychiatry. 2013;59:73-8.

11 Nishida M, Kikuchi S, Fukuda K, Kato S. Jogging therapy for hikikomori social withdrawal and increased cerebral hemodynamics: a case report. Clin Pract Epidemiol Ment Health. 2016;12:38-42.

12 Komori T, Makinodan M, Kishimoto T. Social status and modern-type depression: a review. Brain Behav. 2019;9:e01464.

\section{Measures to reduce smoking: Brazil takes the lead}

Braz J Psychiatry. 2020 Jul-Aug;42(4):456-457

doi:10.1590/1516-4446-2020-0853

(cc) BY-NC

Smoking remains a major global public health challenge. About 8 million people die every year from tobacco use worldwide, of which 7 million occur from tobacco use and about 1.2 million non-smokers die due to passive consumption. Tobacco is also responsible for a high economic outlay, since smoking costs about USD 1.4 trillion each year, including health and productivity expenditures. ${ }^{1}$
The 7th edition of the Global Tobacco Epidemic Report, recently published by the World Health Organization (WHO), ${ }^{2}$ shows that several countries are making efforts to implement tobacco control policies. Since the adoption of the WHO Convention on Tobacco Control Framework (WHO FCTC) in 2003, much progress has been made in fighting smoking. Among the various articles of this convention, MPOWER tobacco control is an essential tool for helping countries adopt measures to reduce smoking. It is an evidence-based intervention instrument and, so far, 23 countries have adopted these guidelines, reaching a population of 24 billion people. ${ }^{3}$

The meaning of the acronym MPOWER is: $M$ monitoring tobacco use and prevention policy; $\mathrm{P}$ - protecting people from tobacco smoke; $\mathrm{O}$ - offering help to quit tobacco use; W - warning about the dangers of tobacco; $E$ - enforcing bans on tobacco advertising, promotion, and sponsorship; and $\mathrm{R}$ - raising taxes on tobacco.

Only two countries worldwide have adopted all MPOWER measures at the best practice level: Brazil and Turkey. ${ }^{2}$ Figure $1 \mathrm{~A}$ shows the chronology of the MPOWER measures adopted in Brazil.

Epidemiological studies on drug use in Brazil show that implementing these smoking control measures shows good results. Figure 1B shows the prevalence of lifetime use and heavy tobacco use (20 or more times in the last month) among elementary, middle and high school students (ages 10-18). The Centro Brasileiro de Informações sobre Drogas (CEBRID) conducted six epidemiological studies using the WHO's methodology. ${ }^{4}$ Students filled out self-completion questionnaires in the classroom anonymously, so their confidentiality would be ensured. The surveys conducted among public school students in the 10 largest Brazilian state capitals occurred in: 1987 (16,324 students), 1989 (8,993 students), 1993 (24,634 students), 1997 (15,501 students), 2004 (48,155 students), and 2010 (31,280 students). ${ }^{5}$ The results showed decreasing percentages of lifetime use only in the 2004 survey. Heavy tobacco use also had the same downward trend (Cochran-Armitage test for trend, $\mathrm{p}<0.05)$.

The decrease in lifetime tobacco use between 2004 and 2010 is also consistent for both genders: from 
A
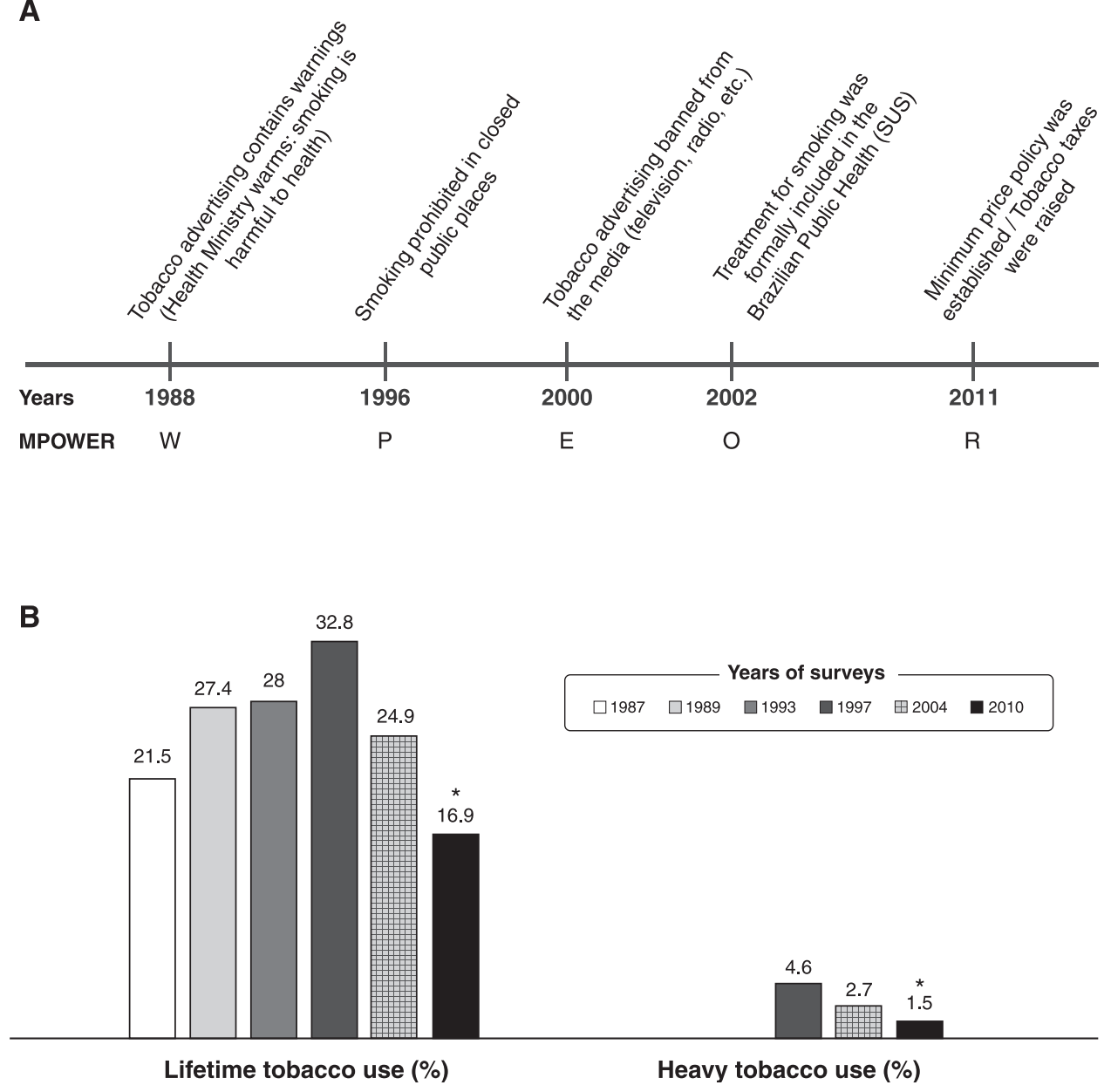

Figure 1 A) Chronology of the MPOWER measures implemented in Brazil. B) Comparison of lifetime use (1987 to 2010) and heavy tobacco use (1997 to 2010). Surveys of public elementary to high school students in Brazil. * Statistically significant decrease $(p<0.05)$, Cochran-Armitage test for trend.

$25.2 \%$ in 2004 to $17.1 \%$ in 2010 among boys; and from 24.7 to $18.6 \%$ among girls. The decrease was also significant in the 10 to 12 age group ( 7.0 to $4.1 \%$ ), the 13 to 15 age group (24.7 to $16.0 \%)$, and the 16 to 18 age group (39.7 to $29.1 \%$ ) (chi-square test, $p<0.05$ ). Apparently, the decrease in tobacco use among adolescents is related to the ban on advertising that began in Brazil in 2000.

\section{José C. Galduróz, iD Nadia Tomita,} Andréia G. Bezerra iD Departamento de Psicobiologia, Universidade Federal de São Paulo (UNIFESP), São Paulo, SP, Brazil.

Submitted Jan 13 2020, accepted Jan 29 2020, Epub May 112020.

\section{Acknowledgements}

This study received financial support from Associação Fundo de Incentivo à Pesquisa (AFIP), Conselho Nacional de Desenvolvimento Científico e Tecnológico (CNPq), and Centro Brasileiro de Informações sobre Drogas (CEBRID).

\section{Disclosure}

The authors report no conflicts of interest.

How to cite this article: Galduróz JC, Tomita N, Bezerra AG. Measures to reduce smoking: Brazil takes the lead. Braz J Psychiatry. 2020;42:456-457. http://dx.doi.org/ 10.1590/1516-4446-2020-0853

\section{References}

1 Goodchild M, Nargis N, Tursan d'Espaignet E. Global economic cost of smoking-attributable diseases. Tob Control. 2018;27:58-64. Erratum in: Tob Control. 2018;27:478.

2 World Health Organization (WHO). Tobacco [Internet]. 2019 Jul 26 [cited 2020 Jan 10]. www.who.int/news-room/fact-sheets/detai/tobacco

3 World Health Organization (WHO). Framework convention on tobacco control [Internet]. 2003 [cited 2020 Jan 10]. www.who.int/fctc/ text_download/en/

4 Smart RG, Hughes PH, Johnston LD, Anumonye A, Khant U, Medina-Mora ME, et al. A Methodology for student drug-use surveys. Offset Publication 50. Geneva: WHO; 1980.

5 Galduróz JF, Fonseca AM, Noto AR, Carlini EA. Decrease in tobacco use among Brazilian students: a possible consequence of the ban on cigarette advertising? Addict Behav. 2007;32:1309-13. 